\title{
Reseñas
}

\section{¿Se agota la democracia constitucional? MAXIMILIANO FERRERO'}

\author{
Reseña de: \\ Roberto Gargarella, La Derrota del Derecho en América Latina. Siete Tesis. Buenos \\ Aires, Siglo XXI, 2020.
}

En este último libro, Roberto Gargarella retoma algunos de los tópicos centrales que ha trabajado en importantes obras anteriores como Los Fundamentos legales de la desigualdad y La Sala de Máquinas de la Constitución. Así, renueva en este pequeño, aunque provocador texto, su idea de que para entender las raíces de las crisis que aquejan a las democracias constitucionales latinoamericanas es necesario atender a sus aspectos estructurales. Es decir, es menester buscarlas en las instituciones heredadas del constitucionalismo del siglo XIX, estabilizado a partir de lo que el autor suele llamar un "pacto liberal-conservador" y cuyo espíritu se ha mantenido más o menos intacto a lo largo de más de un siglo y medio de vida constitucional en Latinoamérica. Este pacto significó el establecimiento y consolidación de diseños constitucionales que, en la geografía latinoamericana, coinciden en la disociación entre las secciones dogmática y orgánica de los textos constitucionales. Organizado en un prefacio y siete tesis, este texto de lectura ágil no solo se esfuerza por poner en la agenda de las discusiones públicas los problemas institucionales de nuestras democracias, sino que identifica, además, sus causas y propone algunas pistas para salir de los mismos.

Las primeras cinco tesis del libro apuntan a identificar las causas de la crisis institucional de las democracias latinoamericanas que fueron convirtiéndose en lo que el autor denomina "regímenes políticos exhaustos" (p. 63). La mayor parte de las críticas que encontramos en el libro se asientan sobre la creencia de que el constitucionalismo nacido de las Revoluciones atlánticas de fines del siglo XVIII "se encuentra en una crisis difícilmente reparable" (p. 12). Así, Gargarella pasa a analizar, en la primera tesis, el problema del deterioro de la representación política. Teniendo en cuenta el constitucionalismo norteamericano, el autor afirma que la 
representación política fue concebida con el fin de impedir que una facción de la sociedad pudiera oprimir o dominar a las otras, como, por otra parte, lo deja en claro Madison en el número $X$ de El Federalista. La solución propuesta a este problema por aquel constitucionalismo fue el de incluir en las instituciones, representantes de los diferentes sectores sociales (ricos, pobres, propietarios, campesinos) suponiendo que la sociedad entera podía quedar representada y otorgarles, además, un poder institucional equivalente como forma de moderar el conflicto social. A ello se dirigió el sistema de pesos y contrapesos. La primera crítica que se puede realizar a este argumento es de carácter sociológico, ya que nuestras sociedades no se componen de sectores internamente homogéneos, sino que se presentan "diversas, plurales, multiculturales" (p. 18) y en las que la identidad de las personas se identifica con rasgos diferentes y difícilmente adscriptas en un sector específico. La segunda crítica de Gargarella es de carácter normativo y está dirigida al sistema de checks and balances, ya que el mismo vulnera el principio democrático de la voluntad mayoritaria en tanto materialización del autogobierno colectivo, al anteponer un balance de poder entre diferentes sectores numéricamente dispares. Cabría señalar, no obstante, que, frente a los peligros del populismo (que el propio autor advierte), cuyo rasgo principal es el de aprovechar el vacío representativo, los controles institucionales deberían reforzarse antes que ser dejados de lado.

La segunda tesis pone el ojo sobre los controles endógenos, principalmente le legitimidad democrática del control judicial de constitucionalidad. Éste se asienta sobre una concepción elitista según la cual la racionalidad e imparcialidad en las decisiones estaría garantizada "por la reflexión aislada de unos pocos" (p. 27). Es decir, por un conjunto de expertos alejados de las pasiones sociales al cual se le garantizaría su independencia como medio de sostener su imparcialidad. La crítica de Gargarella pasa por señalar la baja intensidad democrática de esta institución contramayoritaria y por no haberse tenido en cuenta el problema de la interpretación de la constitución, dada la posibilidad de aparición de desacuerdos razonables respecto de la interpretación del texto constitucional. Además, Gargarella aborda el problema motivacional en la función judicial, la procedencia de los jueces y la constitución de los tribunales. En resumen, el Poder Judicial fue creado sobre una base elitista, en la que la imparcialidad se vinculaba con la reflexión y ésta, con una clase social específica. Por este motivo, se colocó a los jueces en una situación institucional alejada de la sociedad y se les otorgó la última palabra en asuntos constitucionales, razón por la cual, el autor sostiene que el Poder Judicial se apoya en un principio de "desconfianza a la democracia” (p. 36). 
La tercera tesis traslada el punto de la reflexión de los controles endógenos a los exógenos y pone la lupa sobre el voto, para señalar la "extorsión democrática" (p. 43) que resulta de las infladas expectativas que suelen depositarse en este mecanismo de elección. El voto, según Gargarella, no alcanza a traducir las preferencias ciudadanas, ya que cada persona cuenta con un único voto. Cada sufragio nos obliga a priorizar una demanda u opinión específica para elegir un conjunto de candidatos y votar por un "paquete completo" (p. 44) que suele incluir propuestas que avalamos (igualdad económica, según el autor) y otras que no (corrupción política). De esta forma, el electorado sólo puede manifestar un acuerdo o desacuerdo general que muchas veces nos lleva a votar por políticas que rechazamos para obtener otras que deseamos. Si sumamos a este punto el deterioro de la representación política, la ciudadanía no es capaz de ejercer, a través de los medios que posee, un control adecuado sobre sus representantes. Cabe agregar que, en este apartado, Gargarella parece impugnar todo el sistema institucional sin explayarse por ejemplo en la posibilidad de rediscutir las normas que regulan los sistemas electorales o reforzar instituciones constitucionales de participación ciudadana.

En la cuarta tesis, Gargarella retoma el tema central de sus obras más importantes sobre la historia del constitucionalismo latinoamericano para señalar el quiebre interno que caracteriza a nuestras constituciones de "dos almas" (p. 55). Se refiere de esta forma a la disociación entre las declaraciones de derechos que incluyen los textos constitucionales y la sección relacionada a la organización del poder, lo que el autor suele llamar la "sala de máquinas" de la constitución. Esa disociación se funda en que mientras la primera sección se fue modificando y adquiriendo un carácter más democrático (la extensión y multiplicación de derechos), la sección orgánica mantuvo los lineamientos estructurales del elitismo político del siglo XIX, preservando su carácter verticalista y excluyente, al punto de poner en riesgo generosas concesiones de derechos que pasaron a depender, según el autor, de la discrecionalidad del poder político de turno. La quinta tesis surge como colofón de las anteriores para llamar la atención sobre una "erosión lenta y desde adentro" (p. 6l) de las democracias, que prescinden ya de golpes de Estado, pero que se orientan, a través de pequeños pasos, a gobiernos más autoritarios. A este diagnóstico llega Gargarella, señalando principalmente los escuetos recursos de la ciudadanía para ejercer el control sobre las instituciones y los representantes, la preferencia estructural del sistema por los controles endógenos, la autonomización de unas élites políticas que pueden perseguir su propio interés, independientemente del de la ciudadanía, lo que en América Latina, se ve agravado por el desbalance del poder hacia los 
Ejecutivos. Así, intenta mostrar Gargarella, que el amplio espacio que separa a la ciudadanía de sus gobernantes no es un problema imputable a uno u otro gobierno, sino a los principios (políticos, jurídicos y filosóficos) que sustentan las instituciones.

Finalmente, la sexta tesis se apoya sobre dos pilares, el de la autonomía individual, esto es, que "cada persona debe ser dueña de su propia vida" (p. 67) y el del autogobierno colectivo o que "cada comunidad debe ser dueña de su propio destino" (p. 67) para proponer un ideal regulativo que el autor denomina una "conversación entre iguales" (p. 69), como medio de acercar los procesos de tomas de decisiones. Esta conversación entre iguales debería, en primer lugar, incluir tantos potenciales afectados por las decisiones colectivas como sea posible. Esto, tanto por motivos democráticos como epistémicos, ya que, de no tomar los puntos de vista ajenos, perdemos información que contribuya a corregir nuestros propios errores. Además, esas voces dispares deben no sólo expresarse, sino dialogar entre ellas, de ahí que las formas directas de democracia no encajen en este modelo regulativo porque "menosprecian el valor de ese proceso de debate previo" (p. 7I). Finalmente, para que el diálogo se funde en una verdadera igualdad, ninguna de las partes debería poder acabar discrecionalmente el debate. Por último, el texto termina, en la séptima tesis, aludiendo a la ética profesional de quienes ejercen el derecho.

La brevedad del texto no profundiza, por ejemplo, en los supuestos filosóficos o en los horizontes prácticos de realización de un diálogo entre iguales, pero cada punto analizado por el autor es una invitación a repensar y discutir una agenda de problemáticas de cara a un constitucionalismo para el siglo XXI. 